\title{
Frequency and Causes of Vaginal Hemorrhage outside Pregnancy in Women of Reproductive Age at Bonzola Hospital, Mbuji-Mayi, DRC
}

\author{
Kaya Tompa Brigitte ${ }^{1}$, Ciamala Mukendi Paul', Nzembu Kabwasa Peter ${ }^{1}$, Kanyiki Katala Moses ${ }^{2}$, \\ Ntumba Mukendi Kennedy', Jean Mukendi Mukendi Rene', Kolela Kolela Alain'1, Ilunga Bimpa Cedric ${ }^{1}$, \\ Cibangu Muana Wamuenyi Franck ${ }^{1}$, Kaseka Ciswaka Jeanneㄹ, Amuli Jiwe Jean-Pierre ${ }^{3}$

\footnotetext{
${ }^{1}$ Department of Nursing Education and Administration, Nursing Section, Mbuji-Mayi Higher Institute of Medical Technology, Mbuji-Mayi, Democratic Republic of the Congo

${ }^{2}$ Department of Epidemiology, Community Health Section, Higher Institute of Medical Technology, Mbuji-Mayi, Democratic Republic of Congo

${ }^{3}$ Department of Nursing Education and Administration, Nursing Section, Higher Institute of Medical Technology, Kinshasa, Democratic Republic of Congo

Email: ^kayabrigitte3@gmail.com
}

How to cite this paper: Brigitte, K.T., Paul, C.M., Peter, N.K., Moses, K.K., Kennedy, N.M., Rene, J.M.M., Alain, K.K., Cedric, I.B., Franck, C.M.W., Jeanne, K.C. and Jean-Pierre, A.J. (2018) Frequency and Causes of Vaginal Hemorrhage outside Pregnancy in Women of Reproductive Age at Bonzola Hospital, Mbuji-Mayi, DRC. Open Access Library Journal, 5: e4940. https://doi.org/10.4236/oalib.1104940

Received: September 25, 2018

Accepted: October 28, 2018

Published: October 31, 2018

Copyright $\odot 2018$ by authors and Open Access Library Inc.

This work is licensed under the Creative Commons Attribution International License (CC BY 4.0).

http://creativecommons.org/licenses/by/4.0/

\begin{abstract}
Vaginal haemorrhages outside pregnancy in women of childbearing age are a major public health problem in both developed and developing countries. The purpose of this study was to determine the frequency and causes of vaginal haemorrhage outside pregnancy. This is a descriptive study conducted in the city of Mbuji-Mayi at Bonzola General Hospital, registered from 01 to 31 December 2017; the data were collected transversally. The following observations were made during the study period; 174 women of childbearing age were registered. After analyzing the data, the incidence of vaginal haemorrhage in women of childbearing age was $15.8 \%$ and the main causes were: cervical cancer: $32.7 \%$ and uterine myoma $22.5 \%$.
\end{abstract}

\section{Subject Areas}

Nursing

Keywords

Frequency, Causes, Haemorrhages, Vaginal, Mbuji-Mayi

\section{Introduction}

The Gyneco-Obstetrics service receives in its consultations women who come 
with different reasons in accordance with the different pathologies of which they suffer. Among the reasons, there are vaginal discharges that represent common and spectacular symptoms in women in full evolution and in full procreative activity [1].

However, vaginal hemorrhage is a model of obstetric emergency involving multidisciplinary care. It is most often a complication that will occur unpredictably and brutally, whose diagnosis can sometimes be difficult. These haemorrhages must be reminiscent of the search for the cause and rapid care because every time a woman dies in maternity, it is almost one in two cases of hemorrhage [2].

In France, in studies showing a significant association between uterine hemorrhage and advanced maternal age, it is impossible to know if this is due to a direct link between the two, or if it is simply due to the lack of other risk factors related to age, reflecting the limitations of the adjustment technique. However, advanced maternal age remains a common risk factor for hemostasis hysterectomy in this context [3].

Also in France, a survey conducted by Royer, A., on uterine hemorrhages outside pregnancy, reveals that the frequency was $12.7 \%$ and the most common causes of vaginal hemorrhage were: cervical cancer uterine $30 \%$, tumors of the uterine body: $27 \%$ and tumors of the ovaries: $10 \%$ [4].

In Africa more particularly in Mali, a study on the genital haemorrhages in the gynecology obstetrics department of the hospital of Bamako, concludes that the haemorrhage constitutes the first reason for evacuation. These hemorrhages had etiologies: cervical cancer $22 \%$, uterine myoma $14.4 \%$ and fibrooma $7 \%$ [5].

Moreover, in Cameroon, the maternal mortality rate due to hemorrhage in 2004 reached a rate of $6.4 \%$, whereas it was at $4.7 \%$ in 1997 , despite the efforts made to implement it. Health policies in relation to the Millennium Development Goals include the reduction of maternal mortality [6].

In the Democratic Republic of Congo Kinshasa, studies carried out at university clinics have shown that genital hemorrhage is the leading cause of death with $34.7 \%$ followed by pre-eclampsia/eclampsia with $28.2 \%$ followed by infection with $23.9 \%$. The age group of 40 to 45 years is the most involved in maternal death with $35 \%$ of cases [7].

According to a study conducted by the School of Public Health of the University of Kinshasa at the request of the National Program for Reproductive Health (PNSR), in three provinces: the Province of Kinshasa, Bandundu and Bas-Rhin. Congo $65 \%$ of providers cited shock as the main sign of vaginal hemorrhage [8].

In our Province, more specifically in the city of Mbujimayi, we have observed a high frequency of bleeds outside pregnancy which represent a high morbidity and/or a considerable mortality rate in our hospitals, as in a study carried out on the frequency and etiology of menorrhagia in women of childbearing age at the Dipumba General Hospital was $22.5 \%$ and the main causes of vaginal hemorrhage are: cervical cancer with $30 \%$, ovarian tumors $21 \%$ [9]. 


\section{Materials and Methods}

We performed a retrospective cross-sectional descriptive study in women of childbearing age who experienced vaginal haemorrhage outside pregnancy. The study was spread over a 12-month period from January 1 to December 31, 2017.

Our target population is 174 women with vaginal haemorrhage outside pregnancy who visited Bonzola General Hospital in 2017. Our sampling is comprehensive.

A registration grid was used to collect the study data. The descriptive analysis was carried out by calculating the proportions for the variables, we retained the following parameters: socio-demographic characteristics: (age, level of study, marital status, parity), causes. This study was approved by the Ethics Committee, all information collected from the subjects of the study was and will remain confidential. Likewise, the names of the participants will remain confidential and will not be mentioned in the presentation of the results or associated with the results in any way whatsoever.

\section{Results}

Table 1 shows that the frequency of vaginal haemorrhage in women of childbearing age is $15.8 \%$.

Table 2 indicates that it is the age group 37 and over that holds the top at $39.6 \%$. Regarding the level of study it is the secondary level which is more represented $41.5 \%$. Note that $26 \%$ of common-law women hold the lead and the large multiparas are the majority with $33.5 \%$.

Table 3 shows that the main causes of vaginal haemorrhage in women of childbearing age are: cervical cancer $32.7 \%$ and uterine myoma $22.5 \%$.

\section{Discussion}

Indeed, the results of our studies have shown that the frequency of vaginal haemorrhage outside pregnancy in women of childbearing age in Mbujimayi is $15.8 \%$. The frequency in this study is lower than that observed in our country $34.7 \%$ in 2010 in Kinshasa, [7], and 22.5\% in 2000 in Mbujimayi, [9], it is greater than $6.4 \%$ in Cameroon in 2009 and $12.7 \%$ in France [4].

Looking at Table 2, we find that it is the age group 37 and over that holds the top at 39.6\%. These results go hand in hand with those of Kinshasa in 2010, [7] which also shows that it is the age group ranging from 40 to 45 years. Regarding

Table 1. Frequency of vaginal haemorrhage outside pregnancy in women of childbearing age.

\begin{tabular}{ccc}
\hline Frequency & Effective & Percentage \\
\hline Haemorrhage on pregnancy & 933 & 84.2 \\
Hemorrhage outside pregnancy & 174 & 15.8 \\
Total & 1107 & 100 \\
\hline
\end{tabular}


Table 2. Sociodemographic characteristics of women of childbearing age performing vaginal haemorrhage outside pregnancy.

\begin{tabular}{|c|c|c|}
\hline Characteristics & Effective $=174$ & Percentage \\
\hline \multicolumn{3}{|l|}{ Age/years } \\
\hline $15-25$ & 46 & 26.5 \\
\hline $26-36$ & 59 & 33.9 \\
\hline 37 and more & 69 & 39.6 \\
\hline \multicolumn{3}{|l|}{ Level } \\
\hline Without & 37 & 21.3 \\
\hline Primary & 39 & 22.4 \\
\hline Secondary & 72 & 41.5 \\
\hline University & 26 & 14.8 \\
\hline \multicolumn{3}{|l|}{ Marital status } \\
\hline Singles & 25 & 14.3 \\
\hline Married & 43 & 24.7 \\
\hline Divorced & 39 & 22.4 \\
\hline Widows & 21 & 12.2 \\
\hline Free union & 46 & 26.4 \\
\hline \multicolumn{3}{|l|}{ Parity } \\
\hline Nulliparous & 28 & 16 \\
\hline Primipare & 42 & 24.1 \\
\hline Multiparous & 46 & 26.4 \\
\hline Great multipar & 58 & 33.5 \\
\hline
\end{tabular}

Table 3. Distribution of cases according to the causes of vaginal haemorrhage outside pregnancy.

\begin{tabular}{ccc}
\hline Causes & Effective & Percentage \\
\hline Cervical cancer & 57 & 32.7 \\
Uterine myoma & 39 & 22.5 \\
Ovarian cyst & 34 & 19.5 \\
Vaginal tumor & 25 & 14.4 \\
Tumor of the ovary & 19 & 10.9 \\
Total & 174 & 100 \\
\hline
\end{tabular}

the level of study it is the secondary level which is more represented $41.5 \%$. This is explained by the fact that in the developing world $2 / 3$ of girls who go to secondary school drop out during the year for poverty, family constraints or marriage [10].

Note that $26 \%$ of common-law women take the lead. This means that women in this category use or apply indigenous products to please their partners, which puts them at risk of developing cervical or vaginal cancer [11]. 
The large multiparous women make up the majority with $33.5 \%$. This is also scientifically explained that beyond 40 years of age the woman must be examined regularly to exclude cervical cancer to which they are exposed, it also joins the idea found in France in 2014, the age Advanced maternal remains a common risk factor [3] [12].

The results in Table 3 reveal that the main causes of vaginal haemorrhage outside pregnancy in women of childbearing age in Mbujimayi are: cervical cancer $32.7 \%$ and uterine myoma $22.5 \%$. These results are similar to those of France in 1999, [4] and Mali in 2003 [5], those of and Mbujimayi in 2000 [9].

\section{Conclusions}

The frequency of vaginal haemorrhage outside pregnancy in women of childbearing age is a public health problem that deserves special attention. In order to determine the frequency and causes, the study led to the conclusion that the frequency is $15.8 \%$ and the main causes are cervical cancer $32.7 \%$ and uterine myoma with $22.5 \%$.

The results of this analysis suggest that the frequency and causes of vaginal haemorrhage outside pregnancy in the city of Mbuji-Mayi are comparable to those seen in other cities in the DRC and elsewhere.

However, another study is important to determine the epidemiological profile of women of reproductive age making vaginal bleeding in the city of $\mathrm{Mbu}$ ji-Mayi.

\section{Conflicts of Interest}

The authors do not declare any conflict of interest.

\section{References}

[1] FIGO (2006) Prevention and Treatment of Vaginal Haemorrhage: New Approaches Targeting Environments with Limited Resources, Masson, Paris.

[2] Doridot, V. and Audibert, F. (2000) Genital Hemorrhage of Women Outside Pregnancy AKOS. Encyclopedia Practical Medicine, 1-0680.

[3] Bonnet, M.P. (2012) Postpartum Haemorrhage: Epidemiology and Evolution of Anesthetic Practices and Resuscitation in France. Doctoral Thesis, Pierre-Louis Doctoral School of Public Health, Paris, 20, 27, 28.

[4] Royer, A. (1999) Uterine Hemorrhages Outside Pregnancy, France.

[5] Keita, S. (2003) Study of Uterine Hemorrhages in the Gynecology-Obstetrics Department of Bamako Hospital.

[6] Formulu, J.N., Ngassa, P.N., et al. (2009) Maternal Mortality at the Maternity Hospital of the Yaoundé University and Hospital Center, Vol. 10, Cameroon.

[7] Sengeyi, M. (2010) Frequency and Causes of Genital Haemorrhage, University Clinics. RDC, Kinshasa.

[8] PNSR (2012) Maternal Mortality: Prevention of Dangers in Case of Vaginal Haemorrhage. RDC, Kinshasa.

[9] Ndaya, K. (2000 Determination of Frequency and Etiologies of Menorrhagia, 
HGR/Dipumba, TFC: ISTM/Mbujimayi, inedit.

[10] Anonymous, I. (2000) Schooling of the Girl: “All Girls at School” Geneva.

[11] National College of French Gynecologists and Obstetricians (2006) Item 243: Genital Hemorrhage in Women. National Conference of PU-PH in Gynecology-Obstetrics, Masson, Issy-les-Moulineaux, 243-253.

[12] Graesslin, O. and Derniaux, E. (2008) Functional Uterine Hemorrhages or Idiopathic Menorrhagia: Medical Treatment: Modalities, Effectiveness, Complications. Journal of Obstetric Gynecology and Biology of Reproduction, 37, 384-397. https://doi.org/10.1016/S0368-2315(08)74779-3 